\title{
Plastic landscapes, plastic identities: Akha identity on the threshold of definition
}

\author{
KIM CARTER
}

\section{Abstract}

In his study of communities in upland Southeast Asia, James Scott cites the practice of shifting cultivation as being reflective of state evasion. ${ }^{1}$ The Akha tribe of Northern Thailand destabilises this correlation, and demands a more nuanced notion in which identity is actively negotiated between state intervention and traditional landscape plasticity. While historically employed as a method of state evasion, shifting agriculture has become enmeshed in Akha ritual performance as a signifier of identity. While Scott claims that shifting agriculture implies a divorce from state interaction, the Akha employ subversive agriculture techniques and adopt state policies according to highly localised conceptions. According to Forsyth and Michaud, hill people capitalise upon their capabilities within a shifting political and economic context - with the Akha adopting a system of composite swiddening and invisibly subverting state land use policies. ${ }^{2}$ Under a system Janet Sturgeon conceptualised as 'landscape plasticity', forests can become swidden fields and then revert back to forests as the Akha assert their agency to sustain mutable landscapes that incorporate both present and future use. ${ }^{3}$ Thus, the Akha negotiate boundaries of topography and modernity to subvert state intervention and adopt a plasticity of landscape and identity.

Mobility figures as an indelible rhythm of Akha identity according to their culturally embedded understanding of landscape plasticity. This article will focus on how mobility has informed the relationship between hill tribe and state, and opened new ways of articulating identity for the Akha of Northern Thailand. A logical

\footnotetext{
1 Scott, J.C., 2010, 'State Evasion, State Prevention: The Culture and Agriculture of Escape' in The Art of Not Being Governed: An Anarchist History of Upland Southeast Asia, Yale University Press, Connecticut.

2 Forsyth, T. and Michaud, J., 2011, Moving Mountains: Ethnicity and Livelihoods in Highland China, Vietnam and Laos, UBC Press, British Columbia.

3 Sturgeon, J.C., 2005, 'Landscape Plasticity versus Landscapes of Productivity and Rule: Akha Livelihoods under Nation-States' in Border Landscapes, eds D. Peña \& K. Sivaramakrishnan, University of Washington Press, Washington.
} 
correlation can be drawn between shifting agriculture as a means of state evasion and as the initial driving force for the Akha hill tribe. ${ }^{4}$ However, the definitive separation implied by such a state-tribe dynamic is being challenged by progressive state penetration and a radical subversion of state policies on the part of the Akha. ${ }^{5}$ This article will argue that the Akha people negotiate an identity on the threshold between traditional understandings of landscape plasticity and the state's imposed structures of productivity and rule. First, I will demonstrate the historical viability of shifting agriculture as a method of state evasion, and show how state representations of the Akha serve to underscore this dynamic. Next, I will examine how the Akha tribe responds to state action through subversive agricultural techniques. Finally, I will argue that in refusing state-imposed assimilation, the Akha compartmentalise their identity in an effort to assert their cultural agency while also participating in the market economy.

The Akha tribe was initially sustained through a culture of shifting cultivation as a method of state evasion. As James Scott argues, the settlement and agricultural patterns of hill tribes are not innate or culturally situated, but represent a desire for political autonomy, and in some cases, to avoid contact with valley peoples and the threat of epidemics, forced labour or conscription. ${ }^{6}$ In the Akha case, settlement in Northern Thailand began in the early twentieth century, with migrants originating from Thailand's troubled neighbouring states of Burma and Laos. ${ }^{7}$ In the early 1960s there were approximately 7,000 members of the tribe, a figure which trebled in the late 1980s, reaching 33,000 as a result of escalating conflict in the Shan State of Burma. ${ }^{8}$ In order to sustain their upland livelihoods, the Akha adopted a culture of dry rice and corn subsistence. ${ }^{9}$ Over time, rice became embedded in the tribe's culture, constituting the focus of obligatory calendrical rituals and annual ancestor offerings, and the performance of rituals signified an intrinsic connection with ancestors. ${ }^{10}$ As such, the development of swiddening techniques and construction of Akha identity were mutually constitutive. While Scott argues that the impetus for hill swiddening is not culturally situated, the Akha have progressively adapted their practices as cultural artefacts and their mobile livelihoods have become both physical and characteristically intrinsic markers of identity.

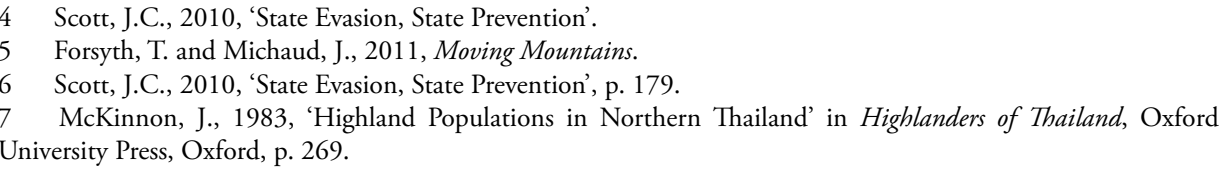


Until the early 1970s, the Akha remained largely isolated from the Thai state and valley dwellers, in a state-dictated arrangement of ignorance and exclusion. In 1973, however, the Thai government instigated policies of social integration as a preventative measure following cases of conflict between ethnic army groups and national troops in neighbouring Burma and Laos. ${ }^{11}$ Moreover, the Thai government engaged in a project of citizenship and state-making that became widespread in the Asian region during the twentieth century, as a result of lingering influences of colonial rule. ${ }^{12}$ The state's nationalistic construction of 'Thai-ness' served as an exclusionary means of demarcating citizenship and property rights. By classifying hill tribes according to scientific models of cultural, linguistic and biological differences bequeathed from European colonial models, the state legitimised stereotypical representations of the Akha as 'backward' and 'primitive..$^{13}$ In the 1990-91 period, authorities conducted a methodical data collection through recording household members as well as taking photographs and fingerprints. ${ }^{14}$ Villagers were issued blue ID cards that distinguished them from those who held white cards of full Thai citizenship. This was done in the interests of national security, which sought to control the tribe's movement and access to resources. ${ }^{15}$ By converting a politically autonomous tribe into a statistical state subject, the state gained control and surveillance over a now largely sedentary tribal population. Within such a dynamic environment, Akha identity operated under an ambiguous mode of statelessness-governed by state laws and policies, but denied equal citizenship rights.

Furthermore, over the course of four decades of highland development from 19602000 , the state engaged in a project of reforestation in celebration of the fiftieth year of the king's reign. During this time, the country's forests were relabelled as state assets and national treasures to be preserved. ${ }^{16}$ The state labelled the Akha as agents of environmental destruction and such representations were directly evident in policies that sought to limit their agricultural activities, which were condemned as threats to the nation's wealth and development. ${ }^{17}$ As with the allocation of ID cards, the state's ownership of forests inhabited by the Akha stemmed from a territorialising bid to control the full extent of Thai space. By claiming the forests as state assets, the government sought to support its program of rapid economic growth based upon capitalist models of development, and state-sanctioned logging companies were permitted to rotate through mountainous regions deemed legally 'unoccupied'. ${ }^{18}$ Furthermore, in an effort to reverse alleged land degradation by the Akha, the state introduced policies encouraging wet rice production on smaller

11 Sturgeon, J.C., 2005, 'Landscape Plasticity versus Landscapes of Productivity and Rule', p. 145.

12 Ibid., p. 26.

13 Sturgeon, J.C., 2005, 'Landscape Plasticity versus Landscapes of Productivity and Rule', p. 145.

14 Ibid.

15 Ibid., p. 182.

16 Ibid., p. 143.

17 McKinnon, J., 1983, 'Highland Populations in Northern Thailand', p. 269.

18 McKinnon, J., 1983, 'Highland Populations in Northern Thailand', p. 269. 
land areas. ${ }^{19}$ Legalised property distribution and ownership were similarly enacted in an effort to create legible landscapes with clearly demarcated property lines and productivity levels evident to state-planners. ${ }^{20} \mathrm{By}$ transforming state invisibilities into statistical subjects and imposing borders upon communal land sharing, the state deprived the Akha of their political autonomy and mobility.

This rigid definition of state borders was followed by the introduction of national frontiers with guarded checkpoints, and replaced the Akha's traditional conception of a space with 'porous [and] indistinct' borders. ${ }^{21}$ The system of centralised bureaucracy undermined the Akha's traditional village structure and precluded possibilities for community ownership of forests that had previously governed understandings of land use. ${ }^{22}$ Under capitalistic modes of production, the Akha became proletariat subjects, as traditional conceptions of working for themselves according to the rhythms of weather were supplanted by a process of disconnected production according to the needs of others. In this way, the Thai government's representation of the Akha people proved instrumental in the construction of policies that not only threatened their land use practices, but destabilised their sense of identity.

Situated within a liminal space of statelessness, the Akha extended their ideas of landscape plasticity, in an effort to reinvent their identity in the face of dissolution. In contrast to Scott's argument, which considers mobility practices as divorced from state interaction, the Akha demonstrate a more nuanced case of adopting state policies according to highly localised understandings. On the one hand, their livelihood changes originated internally, due to a population increase that reduced the available land space and curbed traditional methods of field rotation. ${ }^{23}$ For this reason, in conjunction with a state-exhorted commercialisation of agriculture, the tribe sought to increase productivity and economic stability by relocating to regions strategically located in the vicinity of towns, enabling them access to markets and state services. ${ }^{24}$ As Forsyth and Michaud argue, hill peoples capitalise upon their situation by maximising their capabilities and making attempts to sustain tenable livelihoods as much as they can within a changing political and economic context. ${ }^{25}$ This is evident through the Akha's practice of composite swiddening that incorporates both state-exhorted wet rice and cash-crop production alongside

19 Ibid., p. 271.

20 Ibid., p. 270.

21 Anderson, B., 2006, Imagined Communities: Reflections on the Origin and Spread of Nationalism, Verso, New York, p. 26.

22 Sturgeon, J.C., 2005, 'Landscape Plasticity versus Landscapes of Productivity and Rule', p. 143.

23 McKinnon, J., 1983, 'Highland Populations in Northern Thailand', p. 270.

24 Lyttleton, C., 2011, 'When the Mountains No Longer Mean Home' in Southeast Asia and Everday Life, eds

K.A. Gillogy \& K.M. Adams, Indiana University Press, United States, p. 275.

25 Forsyth, T. and Michaud, J., 2011, Moving Mountains, p. 13. 
shifting cultivation. ${ }^{26}$ On the one hand, the cultivation of cash-crops sedentarised the Akha and limited their ability for flexible land use. At the same time, however, household labour was freed up and redirected to other sources of income such as mining and raising vegetables, thereby diversifying the Akha's agricultural base and income sources. ${ }^{27}$

Moreover, the Akha abandoned their observance of temporal arrangements according to the natural rhythms of weather, along with mutable and long-term time frames that enabled multiple future possibilities for land use. Over time, villagers regulated their time according to the demands of the capitalist market and wage labour. ${ }^{28}$ Despite this shift, however, their land use maintained its complexity and reproduced traditional crop diversity. Farmers clear forest areas to plant upland rice for a year and then allow the land to regenerate into forest-while at other times, they nurture wild fruits, vegetables, medicinal herbs and raise livestock in the surrounding fields and forests. ${ }^{29}$ In this way, the Akha have manipulated their natural environment according to mutable and complex spatial and temporal arrangements in response to 'local needs, state plans and border possibilities' in a process termed by Janet Sturgeon as 'landscape plasticity'. ${ }^{30}$ This plasticity is embedded in the Akha's imagined landscapes that centre upon memory and time-where forests can become swidden fields, and these fields regenerated into forests at a later time. This method ensures optimal land use for day-to-day subsistence and trade, as well as enabling mobility to relocate away from threats posed by state agents. In the mind of the Akha, a single space can oscillate between different uses on a flexible spatial and temporal continuum according to different contexts of subsistence, trade and taxation.

An example of this can be seen in the case of the Thai government's plans to construct a reservoir that would inundate large areas of Akha forests in the Chiang Rai province in order to provide electricity for lowland villages. ${ }^{31}$ In response, the farmers constructed a plan to relocate to an area of land that would regenerate into forest within 15 to 20 years and in the interim, move to pastures downslope and open up land for wet rice cultivation. ${ }^{32}$ This example signifies how the Akha understand land use as processual and highly malleable, and are able to negotiate their daily needs alongside state agents. In another instance of state subversion, land that had been systematically allocated to households was reverted back to collective use, as well as trade and cultivation traversing state-delegated property lines, rules

\footnotetext{
26 Sturgeon, J.C., 2005, 'Landscape Plasticity versus Landscapes of Productivity and Rule', p. 144.

27 Ibid., p. 146.

28 Ibid., p. 144.

29 Ibid., p. 8.

30 Ibid., p. 9.

31 Hanks, L.M., 1964, Bennington-Cornell anthropological survey of hill tribes in Thailand: a report on tribal people in Chiengrai Province, north of the Mae Kok River, Cornell University Press, Michigan, p. 81.

32 Hanks, L.M., 1964, Bennington-Cornell anthropological survey of hill tribes in Thailand, p. 81.
} 
and political boundaries. ${ }^{33}$ It can therefore be suggested that the Akha are not totally divorced from the nation-state, but have instead capitalised on the opportunities provided by political and economic transformations while maintaining their plastic and complex understandings of land use.

An example of the persistent malleability of cultural traditions can be seen through the subsistence farming in the Ban Lorcha village. According to Forsyth and Michaud's notion of cultural agency, the villagers embrace economic incentives provided by the state while concomitantly adhering to Buddhist teachings. As Ratana Tosakul's ethnography demonstrates, villagers practise sufficiency farming based upon Buddhist principles of 'hard work, patience, self-reliance and moderation' as well as restoring the original harmony between the villagers and their natural environment, formerly severed by the penetration of a market-based economy. ${ }^{34}$ By cultivating land according to household requirements and only selling leftover produce, the Akha participate in the market economy while asserting their agency against the demands of capitalism and profit maximisation. The villagers' active protection of the environment challenges the state's projection of them as environmentally destructive, whereas in the past, state-promoted policies of commercial farming rendered the land unusable due to over-cultivation. ${ }^{35}$ With organic farming methods the Akha no longer require the use of harmful pesticides and fertilisers and so have reduced their investment costs for the purchase of chemicals as well as medical expenses resulting from chemical exposure and low-quality food. ${ }^{36}$ Moreover, sufficiency farming provides a sufficiency economy. This model protects farmers from unfavourable market prices biased against the agricultural sector through ensuring consumers pay a fair price and that producers receive a fair share. ${ }^{37}$ In doing so, the villagers have themselves resolved a long-term inequity overlooked by state policy and fostered a sense of agency and control over their livelihoods. In contrast to the state's homogenous and overarching models of development, the Ban Lorcha villagers have created a system that repairs environmental damage, reduces investment costs and manifests a source and sense of self-sufficiency.

Further, where traditional means of mobility according to field rotation have become untenable, the Akha engage in new mobile practices such as migrating to urban areas. By the late 1990s, Akha land area had been dramatically reduced, depriving villagers of the ability to practise landscape plasticity, and forcing a movement toward urban migration. Those who embraced this newfound mobility, largely amongst the younger demographic, gained access to employment, education and medical

33 Ibid., p. 145.

34 Tosakul, R., 2014, 'Alterity to Modernity: Village-Based Self-Sufficient Farm Production in North-eastern Thailand' in Ethnicity, Borders and the Grassroots Interface with the State, ed. JA Marston, Silkworm Books, Chiang Mai, p. 113.

35 McKinnon, J., 1983, 'Highland Populations in Northern Thailand', p. 269

36 Ibid., p. 115.

37 Ibid., p. 117. 
facilities otherwise absent in their isolated communities. ${ }^{38}$ While the Akha proved entrepreneurial, their strategies constituted a shift away from flexible land use and the majority of villagers were too occupied with finding wage labour to counteract this loss of land and traditional cultivation methods. In effect, they were deprived of their ability to plan future trajectories based on land use mutability; an imagined landscape embedded in the Akha mind and identity alike. Instead, having been forced into the capitalist market, the Akha have become consumed with a focus on immediate goals and opportunities for income.

Following this, the Akha community has undergone a process of deculturisation, whereby those who migrate to urban areas cultivate a desire for consumer goods such as electronics, clothing and motorcycles that supplant traditional cultural identifications. ${ }^{39}$ The Akha identity has lost its distinctive quality in a process of interspersion with lowland culture and other highland ethnic groups, as a result of reduced upland space. In her field work, Deborah Tooker noted how one Akha highlander, on entering a store, commented that 'one can't tell if [the others] are Lisu, Akha, Chinese or $\mathrm{Yao}^{40}$ as their distinctive traditional dress is replaced by homogenising modern street clothes. Similarly, the former binaries between 'inside' and 'outside' qualities have been transgressed so that there is no strict separation between participation in wage-based labour or rice-growing subsistence, and locally produced goods are no longer positively esteemed over those produced by lowlanders. ${ }^{41}$ This process of binary deconstruction is evident in how the younger generation traverse the uncertain boundaries of an embryonic identity, to create a duo-identity of Akha/Thai. By contextually remodelling their identity, Akha youth have been granted the opportunity to attend Thai schools, access social services and interact more freely with authorities and outside visitors. ${ }^{42}$ This demand for consumer goods and integration with lowlanders and other highland groups has resulted in an emergent identity on the threshold of Akha and Thai, traditional and modern-most obvious in the overlapping of Thai slang words in speech, and a growing preference for urban street clothes over the traditional blue tunics and distinctive headdresses.

38 Winzeler, R.L., 2010, The Peoples of Southeast Asia Today: Ethnography, Ethnology, and Change in a Complex Region, Rowman Altamira, Maryland, p. 277.

39 Winzeler, R.L., 2010, The Peoples of Southeast Asia Today, p. 278.

40 Tooker, D.E., 2004, 'Modular Modern: Shifting Forms of Collective Identity among the Akha of Northern Thailand', Anthropological Quarterly, vol. 77, no. 2, p. 243.

41 Ibid.

42 Sakboon, M., 2007, 'The Borders Within: The Akha at the Frontiers of National Integration', paper presented to the RCSD International Conference 'Critical Transitions in the Mekong Region', Chiang Mai, Thailand, 29-31 January, viewed 10 May 2015, www.akha.org/upload/documents/theborderswithin.pdf. 
As the Akha's ability to practise traditional spatial and temporal arrangements and rituals diminishes, they have developed a compartmentalisation of identity, demonstrative of both compromise and agency. As aforementioned, the tribe's techniques of shifting cultivation represent the intrinsic basis of their cultural identity and ancestral connection. Thus, restrictions upon their ability to practise flexible land use simultaneously represents a threat to their identity. The demands of capitalism and national integration have created a liminal space for identity definition, where the Akha 'ethnic' identity has been relegated into one of the spheres of everyday life, rather than occupying the central focus. ${ }^{43}$ The Akha ethnicity only receives expression in certain contexts and has become reserved for special occasions, social domains or in the presence of tourist visitors. ${ }^{44}$ For instance, since the Akha now operate according to Thai time, clocking in and out of work and only receiving wages for hours worked, they can no longer practise Akha ritualistic traditions. As a result, practices that centre around the daily and yearly schedule of subsistence rice agriculture, such as offering a chicken to field spirits in the middle of the day, have been abandoned or are performed at a different, non-traditional time..$^{45}$ Traditional subsistence rice agriculture no longer forms the basis of everyday life and economic patterns, and as such, must be relegated into a separate spatial and temporal sphere. An example of this is through the Akha's creation of a separate rice field for growing rice to be used in rituals, as opposed to traditional practice where ritual rice was harvested from the collective crop. ${ }^{46}$ The physical separation of the ritual rice field can be viewed as representative of how the Akha have unravelled the bind between identity and ritual performance.

The compartmentalisation of identity is similarly evident in the tribe's conversion to Christianity. Under a regulated time organisation, flexible temporal structures that governed rituals, such as a 12-day week and activity reserved to daylight hours, rendered their performance burdensome. ${ }^{47}$ As well as this, the villagers' relative poverty following state intervention meant they could not afford the resources necessary to perform sacrificial ceremonies. ${ }^{48}$ By converting to Christianity, the villagers were only required to attend religious ceremonies on Sundays, and for the remainder of the week no ritual practices were required-a comparatively more convenient arrangement than the traditional calendar that delegates auspicious relevance to different days of the week. ${ }^{49}$ Unlike traditional rituals that extensively

43 Tooker, D.E., 2004, 'Modular Modern: Shifting Forms of Collective Identity among the Akha of Northern Thailand', p. 245.

44 Ibid., p. 246.

45 Ibid.

46 McKinnon, J., 1983, 'Highland Populations in Northern Thailand', p. 205.

47 Tooker, D.E., 2004, 'Modular Modern: Shifting Forms of Collective Identity among the Akha of Northern Thailand', p. 251.

48 Ibid.

49 Ibid., p. 252. 
permeated everyday life, Christianity enabled the Akha to relegate spiritual practices to a single day and writ large - their ethnic identity, however reinvented, need only be expressed in a single sphere rather than forming the dominant focus.

Moreover, the compartmentalisation of identity has rendered a performative quality to Akha ethnic identity. This is evident in the reformulation of the New Year, which is now celebrated on the first of January to coincide with the globally observed date, rather than the traditionally auspicious date 25 December. ${ }^{50}$ This suggests a progressive loosening of the bind between local identity and local conceptions of time, and the revision of local traditions within a highly globalised context. Furthermore, the celebrations themselves reveal a performative quality. At a New Year's celebration Tooker attended during her field work, she noted how the construction of a stage paralleled a (re)construction of identity. The Akha language has no word for 'stage' and traditional dancing takes place not as a performative representation, but in the village courtyard as a communal activity. ${ }^{51}$ In a remodelling of identity, the constructed stage becomes a 'delineated sphere' for the performance of Akha culture. ${ }^{52}$ These performances are carried out to preserve rapidly disappearing elements of their ethnic identity, albeit stylised and separate- both in spatial distance from the audience, and from their intrinsically tradition divergent livelihoods. Following a shift in social paradigm, the Akha have compartmentalised their identity to enable their participation in the market economy.

The Akha of Northern Thailand inhabit a liminal space on the threshold between traditional understandings of landscape plasticity and state-imposed policies of productivity and rule. Since the 1970s, in a process of national integration and reforestation, the Thai government instigated policies that limited the land available for the Akha to practise traditional methods of shifting cultivation. Through delegating ID cards that sedentarised villagers while denying them equal rights of citizenship, the state constructed an ambiguous position of statelessness for the Akha tribe. In a radical redefinition of identity and assertion of agency, the Akha participated in state economic projects while maintaining traditional diversity of crops and complexity of land use. The property lines demarcated by the state were invisibly subverted by the Akha and operated according to flexible and porous understandings of landscape. The case of Ban Lorcha village demonstrates how tradition and the demands of a market economy can achieve coexistence and actively foster a sense of agency. Following this, the Akha have adapted new means of expressing mobility in the form of urban migration and exploiting ambiguous identity boundaries to create a dual Akha/Thai identity. Finally, through a compartmentalisation of identity the Akha assert and sustain a connection to

50 Tooker, D.E., 2004, 'Modular Modern: Shifting Forms of Collective Identity among the Akha of Northern Thailand', p. 251.

51 Ibid.

52 Ibid. 
their ethnicity while participating in a capitalist market. As the connection between mobility and identity is loosened and traditional practices have become untenable, the Akha identity has assumed the same plasticity as their conception of landscape.

\section{Bibliography}

Anderson, B. (2006). Imagined Communities: Reflections on the Origin and Spread of Nationalism. New York: Verso.

Forsyth T. \& Michaud J. (2011). Moving Mountains: Ethnicity and Livelihoods in Highland China, Vietnam and Laos. British Columbia: UBC Press.

Hanks, L.M. (1964). Bennington-Cornell Anthropological Survey of Hill Tribes in Thailand: A Report on Tribal People in Chiengrai Province, North of the Mae Kok River. Michigan: Cornell University Press.

Kammerer, C.A. (1987). 'Minority Identity in the Mountains of Northern Thailand: The Akha Case', Southeast Asian Tribal Groups and Ethnic Minorities: Cultural Survival Report (Human Rights Documents) 1298(22), 85-96.

Lyttleton, C. (2011). 'When the Mountains No Longer Mean Home'. In K.A. Gillogy \& K.M. Adams (eds), Southeast Asia and Everyday Life (pp. 273-282). Bloomington, Indiana: Indiana University Press, United States.

McKinnon J. (1983). 'Highland Populations in Northern Thailand'. In John McKinnon \& Wanat Bhruksasri (eds), Highlanders of Thailand. Oxford: Oxford University Press.

Sakboon, M. (2007). 'The Borders Within: The Akha at the Frontiers of National Integration', paper presented to the RCSD International Conference 'Critical Transitions in the Mekong Region', Chiang Mai, Thailand, 29-31 January. Retrieved from www.akha.org/upload/documents/theborderswithin.pdf (accessed 10 May 2015).

Scott, J.C. (2010). 'State Evasion, State Prevention: The Culture and Agriculture of Escape'. In The Art of Not Being Governed: An Anarchist History of Upland Southeast Asia (pp. 178-218). Connecticut: Yale University Press.

Sturgeon, J.C. (2005). 'Landscape Plasticity versus Landscapes of Productivity and Rule: Akha Livelihoods under Nation-States'. In D. Peña \& K. Sivaramakrishnan (eds), Border Landscapes (pp. 142-200). Washington: University of Washington Press.

Tooker, D.E. (2004). 'Modular Modern: Shifting Forms of Collective Identity among the Akha of Northern Thailand', Anthropological Quarterly 77(2) doi. org/10.1353/anq.2004.0073 
Tosakul, R. (2014). 'Alterity to Modernity: Village-Based Self-Sufficient Farm Production in North-eastern Thailand'. In J.A. Marston (ed.), Ethnicity, Borders and the Grassroots Interface with the State (pp. 103-121). Chian Mai: Silkworm Books.

Winzeler, R.L. (2010). The Peoples of Southeast Asia Today: Ethnography, Ethnology, and Change in a Complex Region. Maryland: Rowman Altamira. 
This text is taken from The ANU Undergraduate Research Journal, Volume Eight, 2016, edited by Daniel McKay, published 2017 by ANU eView, The Australian National University, Canberra, Australia.

dx.doi.org/10.22459/AURJ.08.2016.12 